\title{
The Reality of Rhetoric in Information Systems Adoption: A Case Study Investigation of the Uk National Health Service
}

\author{
Imran Khan and Elaine Ferneley \\ University of Salford, \\ Salford, United Kingdom
}

\begin{abstract}
The UK National Health Service is undergoing a tremendous IS -led change, the purpose of which is to create a service capable of meeting the demands of the 21 st century. The aim of this paper is to examine the extent to which persuasive discourse, or rhetoric, influences and affects the adoption of information systems within the health sector. It seeks to explore the ways in which various actors use rhetoric to advance their own agendas and the impact this has on the system itself. As such, the paper seeks to contribute to diffusion research through the use of a case study analysis of the implementation of an Electronic Single Patient Care Record system within one UK Health Service Trust. The findings of the paper suggest that rhetoric is an important and effective persuasive tool, employed by system trainers to coax users into not only adopting the system but also using the system in a predefined manner.
\end{abstract}

Keywords: Rhetoric, NHS, healthcare systems, diffusion theory, social actors.

\section{Introduction}

The UK's National Health Service (NHS) is in the midst of a metamorphosis aimed at modernizing and transforming the organization to one that befits the 21 st century. The drive for modernization is founded upon the design and implementation of new information systems into every facet of the organization, thereby homogenizing the NHS by means of harmonious systems among the various Trusts and Practices. The adoption of information systems into organizations has been examined and addressed by the diffusion of innovations theory, which has spawned significant interest within the Information Systems community and, as such, it is one wing of the IS library to which authors have made significant contributions during the field's relatively brief history (Agarwal and Prasad 1997; Moore and Benbasat 1991; Mustonen-Ollila and Lyytinen 2003).

While the various diffusion theories approach the topic of IS adoption from a number of angles, we would suggest that such models universally fail to account for an important element in human interaction and discourse: the notion of rhetoric. Rhetoric, while informing a number of studies in other fields (Hamilton 2003), has thus far been relatively neglected by IS researchers. The term rhetoric is generally 
misunderstood due to the negative connotations we now associate with the word, but in its true sense it is closely linked with the notion of persuasion (Cockcroft and Cockcroft 1992, Watson 1995). It is in this context that we suggest that it can contribute to our understanding of IS diffusion and adoption, given that Rogers' original concept of diffusion identifies persuasion as an integral part of the innovation decision process (Papazafeiropoulou 2004; Rogers 1995). In this regard, an investigation of rhetoric provides a means through which to appreciate the nuances of persuasive discourse, in that it allows one to "extract a deeper understanding of some of the intrinsically argumentative aspects of discourse" (Hamilton 1998, p. 435), while also creating reality through the construction and use of social structures (Sillince 2006).

We are in the midst of exploring the issue of rhetoric within IS diffusion through a case study exploration of the UK's NHS, which is in the midst of a politically engineered modernization program referred to as the National Programme for IT or NPfIT (NAO 2006). Previous studies have shown that the organization as a whole has not traditionally been particularly receptive to the introduction of new information systems (Eason 2007), especially as it is a highly differentiated environment (Clegg and Sheppard 2007), consisting of a multitude of different groups and professional allegiances set within the politically sensitive, risk-averse arena of the UK public sector (Wainwright and Waring 2007).

In that light, this research seeks to present a case study informed by Lamb and Kling's (2005) concept of the social actor, used in response to the multiple "actors" who are to engage with the system (e.g.,clinicians, administrative personnel, trainers, information managers) and whose multifaceted interaction with the system and one another, we argue, cannot be fully understood by the thin label of user. The research will explore the role that rhetoric can make to diffusion theory and in doing so may help to negate some of the criticisms directed at diffusion theory with respect to its limited appreciation of cultural, social, and contextual issues (Vega et al. 2007). As a result, the ultimate aim of the research is to contribute constructively to the diffusion theory literature by means of enhancing diffusion theory such that it takes greater heed of the cultural, social, and contextual issues. In this regard, our research question is as follows:

Can the diffusion of information systems within the health sector be better understood through an examination of the rhetorical discourses that flow between different social actors?

The reminder of this paper is organized in such a manner as to present a review of the literature concerning both diffusion theory and rhetoric, followed by our theoretical model and research method. We then present our case study, after which we present our analysis and findings before concluding the paper.

\section{Literature Review}

As mentioned in the introduction, there are a wide range of diffusion theories that perforate the field and upon which one can found one's research. As such, in attempting to negotiate these various approaches and theoretical standpoints, there appears little in the way of consensus as to an agreed common ground. Indeed, 
McMaster and Wastell (2005) note that "from an analysis of several hundred citations in the IS diffusion literature, as few as 3 percent of the total could be described as representing a common or shared knowledge in the field" (p. 387).

The literature has, if anything, clouded our understanding of adoption and diffusion (Ramdani and Kawalek 2007) and is accorded by Kautz et al. (2005) the unwanted distinction of being fragmented, unobjective, and generally weak. Vega et al. (2007) suggest that these approaches have thus far neglected or failed to appreciate the cultural assumptions ingrained within an IS or software artefact, which can at best be abrasive to the culture of the host organization, or, in the worst case, totally incompatible with the context in which it is to serve. They thus lament the lack of studies that regard the contextual influences of adoption and diffusion, while at the same calling for studies to broaden their approach to include suppliers and the government. This is of particular relevance for a study centered within the NPfIT, in which the infusion of information systems into NHS Trusts is very much at the behest of the government and enacted by various IS vendors.

Vega et al.'s criticisms were voiced at the 2007 Working Conference of the International Federation for Information Processing's (IFIP) Working Group 8.6 on the Diffusion, Transfer, and Implementation of Information Technology, an event firmly established within the Information Systems calendar since its inception over a decade ago. Casting a curious glance across the proceedings from that initial conference, the authors are immediately struck by a sense of déjà vu; A number of authors (Mumford, Galliers, Kautz) from that original conference raised concerns with regard diffusion theory studies similar to those voiced by Vega and his colleagues. Not only this, the first proceedings from an IFIP WG 8.6 conference gave particular consideration to incorporating socio-technical issues into the diffusion model first suggested by Rogers. Kautz (1996), for instance, anchors his research within an interpretative framework as a means of identifying factors that may sway the adoption and diffusion process one way or the other. In doing so, he suggests that "such a perspective uncovers cultural and political elements" (p. 93), an objective which on the surface appears to placate some of the objections presented by Vega et al.

An additional voice among the dissenters, and one not associated with the IFIP proceedings mentioned above, is provided by Gallivan (2001), who is critical of the traditional diffusionist theories such as Rogers' diffusion of innovations (Rogers 2003) and the technology acceptance model (Davis 1989), given that they do not sufficiently account for situations in which the use of a particular system is mandatory. In their stead, Gallivan proposes a two-pronged strategy that draws attention to both primary adoption by management and decision makers and the subsequent secondary adoption process mandated upon other groups within an organization. Such an approach removes the blinkers imposed by what McMaster and Wastell (2005) term the standard model of diffusion of innovations and the technology acceptance model, thereby allowing issues such as power, context, and culture to enter one's field of vision (Wainwright and Waring 2007) and going some way to appeasing the likes of Vega et al.

A recurring concern within the diffusion literature, and one which appears not to have been satisfied over the past decade judging from recent criticisms, is how to successfully address the so-called softer, fuzzier issues, such as culture and politics, and all that this implies. As such, each successive paper on the subject raises these 
very concerns when reviewing its predecessors while at the same time seeking to solve the very same conundrum. In this respect perhaps it would be prudent return to the source of the theory and the work of Rogers himself, which spawned the work of the authors mentioned previously. Rogers work, while simple, linear, and sequential (Robertson et al. 1996), still beats at the heart of most of the current theories, a piece of work that rests on the innovation-decision process, a five-stage process involving knowledge, persuasion, decision, implementation, and confirmation (Rogers 1983).

Rogers places particular importance on the persuasion stage, whereby "an individual forms a favorable or unfavorable attitude towards the innovation" (Rogers 1983, p. 174). As such, an individual seeks "social reinforcement from others of his or her attitude toward the innovation" and thus "the individual wants to know whether his or her thinking is on the right track in the opinion of peers" (Rogers 1983, p. 175). In this respect, the persuasion stage within Rogers' original concept of diffusion advocates a distinct link or correlation between an individual's attitude toward an innovation and that of his/her peers and associates. As such, one's own self interests form the fulcrum upon which one evaluates an innovation, with an individual seeking an answer to the question, "what are the innovation's advantages and disadvantages in my situation?"- the answer to which is sought from those around us. In light this, Rogers original theory firmly positions diffusion within a social context in which the subjective opinions of our peers, which may or may not be based upon their actual experience with the innovation, are more accessible and convincing and serve as a persuasive force in our formation of an opinion toward said innovation. This latter point, whereby one party, intentionally or otherwise, seeks to change the opinion of another, is the basis of persuasive discourse or rhetoric as it has come to be known and has been relatively neglected in IS research and more specifically in the diffusion and adoption literature.

While diffusion theory, as prescribed by Rogers, identifies the role of persuasive discourse within the adoption process, it is found wanting when one extends it beyond the neat arena of individual adoption. In this respect, traditional diffusion theory fails to lend itself particularly well in situations similar to those currently transpiring within the NHS, whereby adoption is a multilayered phenomenon in which the decision to embrace a new IS a taken by senior management and the end users are mandated to utilize the system. Such instances are termed contingent authority innovation decisions by Zaltman et al. (1973) and form the basis upon which Gallivan attempts to address a particular limitation of Rogers' theory. Gallivan seeks to address a particular limitation by identifying what he terms primary and secondary adopters, with the latter representing the actual end users of the system and upon whose behalf the primary adopters decide to adopt the system in the first place. In doing so, Gallivan provides a means by which one can begin to examine not only mandatory information system adoption but also how decision makers attempt to persuade users as to the merits of their decisions, thereby facilitating adoption.

Gallivan's work forms the basis upon which Wainwright and Waring (2007) construct their study into the NPfIT, and the template from which they develop their diffusion framework. However, both this latter study and Gallivan's framework gloss over the means by which different actor groups perpetuate their own self interests and thereby impact upon the diffusion process itself. The reader of these texts is lead effortlessly through the stages of various diagrams and frameworks addressing the 
diffusion process, without pausing to examine the interactions and engagements between different actors. As such, one particular critique, which can be leveraged against diffusion studies based on authority innovation decision, is that they fail to successfully address the how: how diffusion takes place in mandated contexts proliferated by actor groups keen to pursue or push their own agendas and whereby social interaction and bonds form an integral part of the opinion process.

The term rhetoric carries with it a negative connotation as illustrated by the Oxford English Dictionary, which acknowledges rhetoric's persuasive nature in that it is the "art of effective or persuasive speaking or writing, especially the exploitation of figures of speech and other compositional techniques," adding that it is "language designed to have a persuasive or impressive effect but which is often regarded as lacking in sincerity or meaningful content." On the basis of this definition, the term is generally regarded with suspicion (Hamilton 2003), although in its purest sense rhetoric was regarded by the ancient Greeks as an art that required skill (Booth 2004) and dwelt upon substantially by the likes of Socrates and Cicero (Bilig 1996). Indeed, Socrates devoted significant energy into its study, culminating in his opus to the subject, On Rhetoric (Olmsted 2006).

Whether one subscribes to the modern day interpretation of rhetoric, as alluded to by the latter part of the OED's definition, or gravitates toward its classical interpretation its link to persuasion is inescapable. As such, Black (2005) sheds some light upon this link, in that "rhetoric is the art of persuading others, therefore rhetoric and persuasion are inseparable since any definition of rhetoric necessarily includes the idea of persuasion" (p. 9).

On such a basis, rhetorical discourse is said to fall into one of three modes of persuasion, which although first identified by Aristotle still permeate rhetorical studies to date (Corbett and Connors 1999). These are logos, ethos, and pathos. Logos is persuasion through reasoning, ethos is that aspect of rhetoric centered upon persuasion through force of personality, and pathos centers upon persuasion through the arousal or manipulation of emotion (Cockcroft and Cockcroft 1992). This triumvirate of devices forms the basis upon which Aristotelian rhetoric is set yet still manifests itself in rhetorical studies conducted today. One such example is provided by Van de Ven and Schomaker (2002), who raise the specter of rhetoric in the possible adoption of evidence- based medicine within a healthcare setting. While not specifically addressing IS, their paper lends itself well to the issue of new IS adoption through its discussion of attempts to introduce an innovative practice. As such, Van de Ven and Schomaker suggest that the adoption of an innovation rests not only upon the argument provided the latter's proponents but also upon their credibility, values, and experience, not to mention the interests of the likely adopters. In this respect, Van de Ven and Schomaker state that "innovations are more likely to be adopted when a convincing argument [logos] is presented by credible proponents [ethos] who stir the interests, needs and emotions of the potential adopters [pathos]" (p. 90).

That said, the authors go on to make the point that adoption of innovations in a healthcare setting is seldom this simple, in that adoption involves communication and negotiation between divergent stakeholders, each of which seeks to further its own interests are far as possible. Van de Ven and Schomaker are not alone in casting a rhetorical net over events transpiring within healthcare given that the NHS also has served as a setting through which to examine rhetoric in use. As such, studies that 
focus on the use of rhetoric within the NHS have enlightened readers as to the role of rhetoric in negotiation (Hamilton 2003), management (Mueller et al. 2004), cultural change (Hughes 1996), and identity formation (Bleakley 2006). Hamilton, in particular, has regularly contributed to the study of rhetoric and has chosen the NHS to anchor his research on a number of occasions, although it must be said that none of his studies consider IS adoption in any way. Hamilton examines the notion of rhetoric as a framework through which one can examine persuasive efforts of different parties in their attempts to influence and convert others to their way of thinking, an example being Hamilton's (2000) paper highlighting a shop steward's use of a number of tropes from rhetoric's repertoire through which he tilts the negotiations in his favor.

Hamilton's work, as well as the work by Mueller et al. (2004) and Hughes (1996), demonstrates the true nature and role of rhetoric, in that there is far more substance to rhetoric than the modern day colloquial use of the word suggests. As such, pausing to examine the use of the term rhetoric among publications of an IS nature reveals that it is very much cast as the villain of the piece: usage suggests a lack of substance or a veneer beneath which the truth lurks (as in style versus substance) and is epitomized by titles that feature a phrase containing "rhetoric" and/or "reality" after a conjunction (Ennew and Fernandez-Young 2006; Hartley et al 2002; Moon 2002; Orlikowski and Baroudi 1989).

Returning to the issue of rhetoric as persuasive discourse, one can build upon Aristotle's rhetorical triangle by classifying the rhetoric in use by means of Booth (2004) and his trident of deliberative, forensic, and epideictic rhetoric. The first form is that concerned with attempts to construct the future and is a particular favorite of politicians and forms of policy makers. The forensic form of rhetoric is very much regarded as the domain of historians and lawyers, in that it is concerned with interpreting past events, epideictic rhetoric is firmly centered within the here and now and aims to shape one's interpretation of the present. These forms of rhetoric are not mutually exclusive and it is through exposure that our realities are questioned and formed, where one can seek to persuade or elicit agreement by creating a vision of the future (deliberative), (re)interpreting or manipulating the past (forensic), or reshape views of the present (epideictic). Booth eloquently states that "when words and images remake our past, present or future, they also remake the personae of those of us who accept the new realities" ( $p$ 17).

\section{Theoretical Framework}

When attempting to recall a diagrammatical representation of Rogers' diffusion of innovation theory, one is invariably reminded of the classic bell curve graph, which surfaces throughout the pages of his work. The graph purports to depict the frequency with which an innovation is adopted, with Rogers allocating sections of the curve to the five classifications into which all adopters can be designated. As such, Rogers refers to this model as the "adopter categorization on the basis of innovativeness" and in itself it does not represent a framework for his theory.

In order to find something a little more representative of Rogers' work, it is necessary to cast one's gaze toward his notion of the innovation decision process to which 
reference was made earlier. Rogers' liking for the number five is in evidence once again in his proposition as to a five stage model through which an individual traverses when engaging in the adoption process. By his own admission, Rogers' model is sequential, and is geared toward an individual afforded the liberty of whether to except or reject a new innovation. In this respect, Rogers supplements the framework with an additional model geared toward organizational adoption, but this too is guilty of the fallibilities leveraged against the individual model by the likes of Gallivan (2001) and Robertson et al. (1996).

According to the model, an individual (or organization) first acquires or gains knowledge as to a new innovation, after which s/he enters a persuasion stage. In this respect, we would suggest that the Rogers' model has a flatness to it which does not take into account the way various actors shape and mold one another's opinions. This is epitomized by Rogers' persuasion stage whereby one finds an almost one-to-one relationship between the innovation and the adopter, an exclusivity to which third parties have limited influence.

A further issue as to the model centers on the issue of knowledge of an innovation, particularly in an organization in which adoption is mandatory. While Rogers does indeed acknowledge the fact that this is often the case, going so far as to designate such instances as being "authority innovation-decisions" (1983, p. 29), he does not take this any further, therefore failing to integrate this into his model and thus rendering his theory nonrepresentative of the type of information systems diffusion that is currently under way within the context of this study. As such, Roger's framework does not sufficiently address the dynamism of adoption, especially in a context proliferated with multiple social actors. In this respect, we would suggest the answer lies in a re-reading of Rogers' identification of the main elements of diffusion. Rogers suggest that "the main elements in the diffusion of a new idea are (1) an innovation (2) that is communicated through certain channels (3) over time (4) amongst members of a social system" (1995, p. 11) and it is to the latter part of this definition that the answer may lay. As such, we propose that it is the notion of a social system that has been insufficiently addressed in previous conceptualizations of diffusion and an area to which rhetoric can be of use.

The mandatory diffusion of IS into the health service invariably involves and affects a range of different actors with differing agendas. These actor groups represent and form the social system(s) espoused by Rogers (1983), (re)creating and reinforcing the opinions and understanding of those found within their ranks. This particular sentiment, that of the social formation of individual thought, forms an integral part of the teachings of French philosopher Pierre Bourdieu and is formalized in his notion of habitus (Bourdieu 1992). Allowing for, and in fact actively incorporating, habitus into one's conceptual development allows for the consideration of social constraints on the formation of knowledge and, as such, is described by Mutch (2003) as a means by which to examine how "patterns of though are unconsciously acquired and the links between social actors and their backgrounds" (p. 388). In this respect, both habitus and Bourdieu himself have lent themselves to a number of IS studies (Mingers 2004; Mutch 2003), as well as those specifically concerned with diffusion (Kvasny and Truex 2000), and allows for a greater understanding as to the introduction of new IS, not to mention the subsequent rippling affects. In this respect, when fixing one's gaze firmly upon diffusion, as is the case of 
this study, Bourdieu's habitus facilitates the "exploration of expectations, aspirations, and attitude towards technology, in addition to how and if one engages technology" (Kvasny and Truex 2000, p. 284)

That said, the questions arises as to how habitus fits in the purpose of this study, one which seeks to determine the role of rhetoric and persuasion on the diffusion of information systems. The answer, we would suggest, lies in the fact that our understanding and interpretation of the world around us is in a state of flux, we share our understanding of the world with those around us and, therefore, habitus is both an individual and shared concept (Kvasny and Truex 2000). In light of this, habitus is durable yet not fixed and is "malleable and in constant negotiation with the world" (Kvasny and Truex 2000, p. 283). If mandatory adoption is to be imposed upon a social group, as is the case in the NHS and the NPfIT, it is the individual and collective habitus of said group which must be permeated and changed, and is it rhetoric, we suggest, which facilitates this end.

Adapting Rogers' framework to take into account persuasive discourses that flow between the social actors functioning within the NHS, we propose a rhetorical cycle in which actors from one group redefine their own thoughts and opinions while also trying to change the habitus of those around them. This cycle suggests that diffusion is not a linear process as espoused by Rogers, nor is persuasion simply a stage that must be traversed on the way to the ultimate adoption of a new technology (Figure 1). Rather, the social actors in the diffusion process are continually seeking to persuade and influence one another, utilizing their relationships, strength of argument, and emotions to do so (pathos, logos, and ethos).

\section{Research Method}

This study gravitates toward the interpretative tradition of IS research but will adopt aspects of critical hermeneutics as a means of infusing the study with rigor, enabling one to "portray the real complexity of organizations as social, cultural and political systems... allowing the researcher to look at information systems through the different perspectives of various stakeholders and real value conflicts there may be" (Myers 1997, p. 250).

Critical hermeneutics, therefore, bridges the divide between the interpretivist and critical schools of thought and has been developed from the philosophical hermeneutics of Gadamer by theorists such as Ricour (Thompson 1981), who have sought to infuse hermeneutics with elements of critical theory. It has germinated from the discussions between Habermas and Gadamer, in so far as there are commonalities between the thoughts of the two theorists and elements within their writing which are complimentary. As such, Bernstein (1984) has shown that critical theory based upon the thought of Habermas and philosophical hermeneutics espoused by Gadamer, while different and diverse in many respects, are not totally antagonistic or dichotomous. Within information systems, Myers $(1994,1997)$ is the main advocate of a critical hermeneutic approach, using it to examine IS failure within the health sector and issues such as the exercise of power among IS professionals. 


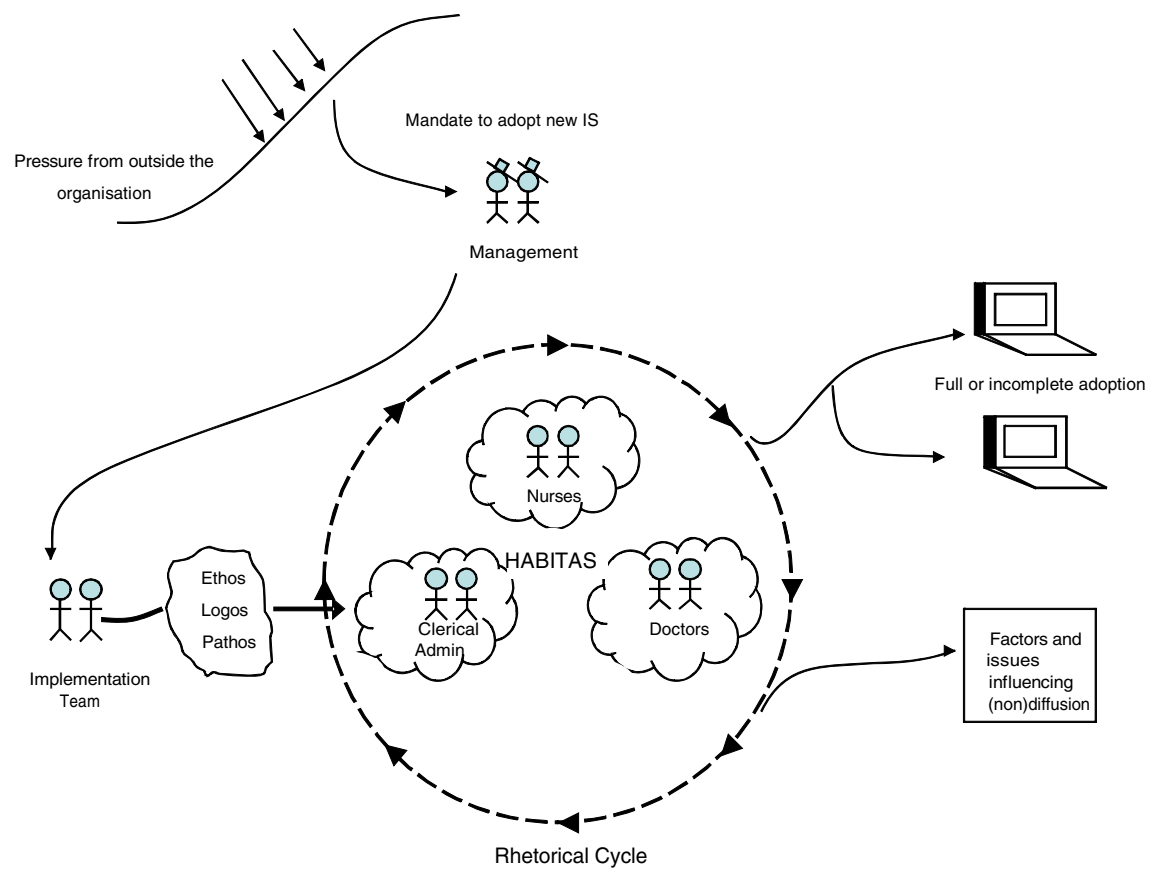

Fig. 1. Conceptual Model

The advantages of employing a critical hermeneutic approach, as far as this research is concerned, are expounded by Myers (2004) in his elevation of a hermeneutic approach in general, whereby the latter enables one to "portray the complexity of organizations as social, cultural and political systems" (p. 123). The application of critical hermeneutics thus affords us the means by which to examine the tide of rhetorical discourses that ebb and flow between the various social actors involved in the diffusion of IS into the research context.

The method by means of which the research will seek to explore the field of study is that of a case study. Research within the NHS is shrouded in bureaucracy and, as such, we have had to engage in a lengthy process to secure ethical approval, the result of which has allowed us to contact, recruit, and interview members of the organization. In addition, we have also obtained permission to attend team meetings. We have conducted a phased interview process whereby information elicited from the research participants was taped and transcribed at a later date. The mode of analysis was that of hermeneutics, whereby the interpretation of the transcripts was in keeping with the context of the study, complementing and supporting our desire to explore persuasive discourse.

We intend to call upon Lamb and Kling's (2005) concept of the social actor to provide greater insight and understanding as to the nature of the various research participants. In this respect, the notion of a user is far too narrow and it is only through an understanding as to the social actors' affiliations, identity, environment, 
and interactions that one can truly begin to appreciate the rhetorical discourse taking place. As a result, the study identifies the following social actors:

- Clinicians-would be conventionally regarded as the end user and include doctors and nurses

- Clinical Leads - former clinicians who have been seconded into the implementation team and are responsible for ensuring the smooth transition to the new system

\section{Case Study}

The NHS has developed a history of IT-led innovation (NAO 2006), albeit one which upon scrutiny its somewhat checkered as far as success is concerned (Clegg and Shepherd 2007). Since the turn of the millennium, the development of an integrated clinical records system has been the focus of the NHS's IT agenda and has manifested itself as various initiatives within the National Programme for IT (NPfIT). These initiatives include the implementation of an electronic single patient care records system, the development of an NHS IT spine, a "choose and books" system to facilitate patient choice, and a picture archiving and communication system.

The full brunt of the NPfIT will be felt at the operational level of NHS, at the various semi-autonomous Trusts which constitute the UK's National Health Service. One such trust is HealthCo Primary Care Trust, which is responsible for the delivery of non-emergency health care to the residents in the local area and is charged with the responsibility of implementing systems such as those responsible for patient records and insuring that the various clinicians and administrative staff are of a sufficient level of competence to use the systems.

The Trust has been allocated a particular variant of electronic patient records system by virtue of the tendering process, whereby CompProvider was awarded the contract for the Trust's geographic location. As such, the system on offer is the Pegasus Community Care system which was implemented as a bare-bones system upon which various layers of functionality are to be added when available. The diffusion of this system into the organization centered on determining the various working practices of the clinicians and tailoring these in such a way as to be fully system compliant. In order to do so, process mapping exercises were held by the clinical leads and the implementation team after which the new processes were introduced by the clinical leads and system trainers.

Problems have arisen as to the performance and usage of the system, with the clinicians wary as to the requirement of the system whereby they must account for all of their time. Management, meanwhile, have voiced their dissatisfaction as to the poor quality of the data extracted from the system and the degree to which the system is actually used by the clinicians. As things stand, clinicians are not entering data into the system on a daily basis as directed, preferring to enter the details of all their patient activities in one go up to two weeks later. The clinical leads, meanwhile, are coming under pressure from management to ensure that the system is used in the correct manner and at the required times. 


\section{Case Study Analysis}

This section seeks to apply our theoretical framework to the above case study, whereby we examine the rhetorical cycle taking place among member of two of the key actor groups within the implementation of NPfIT, the clinicians, who form the primary users of the new system, and the clinical leads, whose role it is to ensure a smooth transition to the new technology.

\subsection{Clinical Leads}

Persuasion through Pathos. Persuasion by means of pathos was a key instrument within the rhetorical cycle taking place, whereby the clinical lead's rhetoric centered on what could be perceived as the manipulation of the clinician's emotions and sense of duty. The clinical lead, when required to justify the need for a change in systems (the clinicians had as far as they were concerned recently adopted a new system which itself has been superseded by Pegasus as a result of the dictates of the NPfIT), retorted that "these systems and services are essential for creating the modern, safer, joined-up NHS to which we all aspire." This served to draw upon the clinicians' collective sense of purpose, especially with the emphasis upon the "we," as with the clinicians, and the hand gesture which accompanied it. (As an aside, it was only later that we discovered that the clinical lead's statement was in fact the mantra of Richard Granger, the former director of the NPfIT).

The clinicians' sense of purpose was a constant target for the clinical lead's rhetoric, with statements such as 'being able to access patients' information is going to help us save lives" as well as "electronic care records will mean patients will have fewer forms to fill in," reminding the clinicians as to why they had originally entered the profession.

Persuasion Using Ethos. Persuasion by means of ethos or strength of personality manifests itself primarily through the clinical lead, who is keen to emphasize her camaraderie and sense of kinship with the clinicians themselves. This is most clearly illustrated by the clinical lead's own assertion that

It's as much about personality as anything else. You've got to have those influencing and negotiating skills to be able to change people's minds about things. Our background is obviously nursing but we have to develop an understanding how other services work and make suggestions of different ways of working. If they're [the clinicians] not for moving, its very much about nudging them to achieve our aims.

Statements such as "I am a nurse. Once a nurse always a nurse" served to soften the attitudes of the clinicians as to their refusal to, in the manager's words "play ball" and use the system in the designated manner.

This initial hard line was overcome by the clinical lead through her continual use of ethos (as well as the aforementioned pathos), reinforcing her understanding of the difficulties encountered by the clinicians to such an extent that the clinicians began to sympathize with the clinical lead's position. Statements such as "we realize you are only doing your job" and "we can see why you would want us to input data on a daily 
basis" contrasted significantly with the initial mood of the group. The clinical lead's assertion that "you don't necessarily have to be doing hands-on nursing care to be able to have an impact on patients care, do you know what I mean?" coupled with her personality and character allowed her to enter the clinician's habitus in a way that was beyond any other member of the implementation team.

Persuasion through Logos. The adoption of Pegasus by the Trust has not produced the desired results in terms of the way in which the clinicians are using the system. The clinical leads are particularly suited to addressing such issues in that they straddle the divide between "us and them," with their clinical background affording them certain privileges in terms of permeating the clinicians' habitus, while focusing on their main role as system implementers.

Their unique position, drawn upon through the use of ethos, allows them to highlight logical reasons as to why clinicians should be more receptive to the new system given that "electronic care records will mean patients will have fewer forms to fill in" Logical arguments are particularly useful when addressing a group of clinicians who have embraced technology and use it on a daily basis for their own ends. Such groups are referred to by the clinical leads as "our champions" in that it is often only necessary to highlight or go through the system's proposed benefits with such clinicians and they are "onboard" with any suggested changes.

The clinical leads make specific reference to a specific clinician who "wears $a$ utility belt of gadgets" as one such champion. That said, the clinical leads are also highly suspicious of such groups, referring to them as "dangerous users" or "uneducated educated users," given that their "use of PDA's and smart-phones" or the fact that "[he] managed to install Windows Vista on his laptop" gives them a "false impression that they know a lot about technology." It is these clinicians who later "bad mouth the technology to others" if it does not meet their expectations.

\subsection{Clinicians}

The Use of Pathos. Rhetoric among the clinicians primarily makes use of their sense of shared purpose and the habitus to which they belong. As such, collective identity of the clinicians was reinforced by statements such as "a necessary evil" when referring to the need to engage with, and produce reports for, management. When one clinician stated that such activities were an aside to the "reason we are all here...to help and treat patients," the rest of the group nodded in approval and another further reinforced the perceived sense of collective purpose when, choosing to speak on behalf of the whole group, she stated that "we feel that clinicians should be practicing nursing rather than acting as data entry clerks!"

The use of the collective "we" serves to unite the clinicians around this one goal while also separating them from the counter-argument that clinicians ought to be more receptive to the use of the new computer system and the additional responsibilities that this brings. Those clinicians with, in the words of one nurse, "horror stories" as to the experience of other clinical teams, continued to draw upon the fact that "we are not IT" (referring to the IT department) in so much that patient care is universally within the group regarded as the central tenet of being a clinician. 
Most telling was the clinicians' use of pathos in the direction of the managers in that "the training does not prepare us to use that system...it's impacting because Monday mornings clinicians aren't out with patients, they are out doing computer work, which is not how we all perceive the clinicians role to be." As if to ensure that no doubt is left in the minds of those present, one senior clinicians draws a line under the whole discussion by declaring that "fundamental change is really about power and control. They just want to keep an eye on us," to which no one in the group offers objections.

The Use of Ethos. The impact of the previous statements was all the more effective given that a number of the more dramatic comments emanated from more senior clinicians, both in terms of age and position. One clinician was particularly vocal as to her opposition to the new system and was keen to elicit examples from younger clinicians as to how their friends and acquaintances in other departments were also encountering difficulties in using the system. Her repeated emphasis as to the fact that "I have been in this job for over 20 years" appeared to grant her the right to speak on behalf of others, while also imbuing her assertions with greater credibility.

Persuasion through force of personality was evident throughout, as the aforementioned clinician continued to highlight her experience and also the experience of others, asserting that "I was here when they brought in the old system, as were you Jean. All that fuss and bother but for what? So that we can go through whole process again. And again and again!" The defiance of the clinician in the face of mandatory use of the system when she stated that "although we've electronic records, I'm still avoiding them and feign ignorance about them all" brought smiles all round, as did her commitment to her patients in that while "the top floor" (management) continue to push the new IT program, "I will just get on with treating and looking after folk."

The Use of Logos. Persuasion through logic does not feature as extensively as the pathos or ethos discussed previously. Those designated as "dangerous users" by the clinical leads sought to emphasize the futility in resisting or dragging one's feet, in that "at the end of the day, the decision has been made that this system is to be used and there is nothing we can do to change that. The sooner we accept that and open our minds to this new technology, the quicker we can get to learning how to use if effectively." These assertions as to logic in using the system were, however, overshadowed by those relying upon personality and emotion to convey and secure their message.

\section{Discussion}

Our case studies help to shed light on a neglected aspect of the adoption and diffusion process, one in which the posturing of the various social actors is examined and analyzed with respect to its impact upon other actors. As such, we argue that introducing a new system into an organization, especially one in which the system is very much seen as something that takes people away from performing their "actual" roles, involves a level of persuasive discourse as a means of not only reducing resistance but also allowing for the possible limitations to the system itself. 
As such, the rhetoric used by the clinical lead to persuade clinicians to use the system, with non-use impacts not only on the service and organization but on the patient and society as well, hits at the very identity of the clinician. An identity at the core of which is the duty to help people, alleviate suffering, and ultimately improve lives (Timmons 2003).

The same can be said of the clinicians themselves, with their ability to deflect criticism from management onto the system implementers who were then instructed to redesign training methods to facilitate the clinicians' adoption of the system and address their concerns. Interestingly enough, the research cast light on how the clinical leads designated those more technologically literate clinicians as "dangerous users," while at the same time seeking to have the same clinicians on their side as their "champions."

Both the clinical leads and the "dangerous user" clinicians approach the system from a certain perspective-that of expert (in the latter's case, this is their own assessment) - and have been more willing to use logic in their persuasive discourse. One possibility for this may be the notion of expert versus novice, with clinicians lacking in knowledge about the system, therefore not feeling confident or comfortable formulating an argument around the notion of logic.

We would suggest, given that the clinicians function within the same habitus, one to which the clinical lead was also privy, that the social actors were far more comfortable and accepting of ethos and pathos, while the trainers, as outsiders, had to confine their persuasion attempts to logic alone. This may also have something to do with the asymmetry of power within the organization, whereby those with a degree of power, such as managers, had the luxury of relying simply on logic to persuade others.

In light of our findings, we argue that the study of IS adoption can be further enhanced through an examination of the rhetorical discourse which takes place between the various actors in the midst of the system. In this regard, diffusion of innovation frameworks such as those espoused by Mustonen-Ollila and Lyytinen (2003) and Gallivan (2001), while embracing contextual issues to a greater extent than previous diffusion of innovation theories (Wainwright and Waring 2007), stop shy of discussing persuasion among actors as a facilitator, or otherwise, of information systems adoption. Furthermore, while persuasion is a key factor within Rogers' innovation-decision process, it is very much regarded as focused upon the adopter and his or her direct interaction with the innovation. Our case study would suggest that not only is the adoption of a system influenced through rhetoric, nonadoption, or unintended outcomes, such as the lack of reports, can all also be addressed in a similar manner, thereby altering perceptions as to what a system can and cannot do. This is of particular relevance when one considers the challenge posed by the implementation of the new system: "The biggest thing about the whole thing isn't the IT or data migration or training. It is the change management of altering the way in which people work" (HealthCo's informatoin manager).

The case has illustrated how rhetoric is used as a tool to increase the adoption of a system and secure support, given that the clinical leads are not only responsible for activities such as process mapping but also "communicating the benefits of the system" to users. In this respect, a particularly telling indicator as to the role of 
Table 1. Intersections of the Two Dimensions of Interest Groups and Mode of Persuasion

\begin{tabular}{|l|l|l|}
\hline & \multicolumn{1}{|c|}{ Clinical Lead } & \multicolumn{1}{c|}{ Clinician } \\
\hline Ethos & $\begin{array}{l}\text { I am a nurse. Once a nurse } \\
\text { always a nurse. }\end{array}$ & $\begin{array}{l}\text { All that fuss and bother but for } \\
\text { what? So that we can go } \\
\text { through whole process again. } \\
\text { And again and again! }\end{array}$ \\
\hline Pathos & $\begin{array}{l}\text { Using the system will ultimately } \\
\text { help save lives. }\end{array}$ & $\begin{array}{l}\text { We feel that clinicians should } \\
\text { be practicing nursing rather } \\
\text { than acting as data entry clerks! }\end{array}$ \\
\hline Logos & $\begin{array}{l}\text { The system will help improve } \\
\text { patient care }\end{array}$ & $\begin{array}{l}\text { The system takes too much of } \\
\text { our time }\end{array}$ \\
\hline
\end{tabular}

rhetoric within NHS IS adoption is the clinical lead's statement whereby "part of the job is to communicate our sales pitch to sell people on the technology. But we also take part in a lot of ego stroking, bigger egos require a lot more stroking....I sometimes feel like a used car salesman!"

\section{Conclusion}

Healthcare organizations continue to invest resources in the development and implementation of information system with the intention of improving efficiency and service. Diffusion frameworks have thus far been found wanting with regard to studying the nature of adoption within these organizations and to this end we have proposed expanding the scope of investigation to include the rhetoric discourse that takes place between the various social actors. In this regard, our study introduces a group of social actors heavily engaged in the diffusion of an information system and whose actions significantly influence the extent to which it is adoptioned.

\section{References}

Agarwal, R., Prasad, J.: The Role of Innovation Characteristics and Perceived Voluntariness in the Acceptance of Information Technologies. Decision Sciences 28(3), 557-582 (1997)

Bernstein, R.J.: Beyond Objectivism and Relativism: Science, Hermeneutics and Praxis. University of Pennsylvania Press, Philadelphia (1984)

Billig, M.: Arguing and Thinking: Arhetorical Approach to Social Psychology. Cambridge University Press, Cambridge (1996)

Black, J.: Politicians and Rhetoric: The Persuasive Power of Metaphor. Palgrave Macmillian, New York (2005)

Bleakley, A.: You Are Who I Say You Are: The Rhetorical Construction of Identity in the Operating Theater. Journal of Workplace Learning 18(7/8), 414-425 (2006)

Booth, W.: The Rhetoric of Rhetoric: The Quest for Effective Communication. Blackwell Publishing, Oxford (2004)

Bourdieu, P.: The Logic of Practice. Polity Press, Cambridge (1992) 
Clegg, C., Shepherd, C.: The Biggest Computer Program in the World..Ever! Time for a Change in Mindset. Journal of Information Technology 22(3), 212-221 (2007)

Cockcroft, R., Cockcroft, S.: Persuading People: An Introduction to Rhetoric. Macmillan Press, Ltd., Hampshire (1992)

Corbett, E.P.J., Connors, R.J.: Classical Rhetoric for the Modern Student, 4th edn. Oxford University Press, New York (1999)

Davis, F.D.: Perceived Usefulness, Perceived Ease of Use, and User Acceptance of Information Technology. MIS Quarterly 13(3), 319-340 (1989)

Eason, K.: Local Sociotechnical System Development in the NHS National Program for Information Technology. Journal of Information Technology 22(3), 257-264 (2007)

Ennew, C., Fernandez-Young, A.: Weapons of Mass Instruction? The Rhetoric and Reality of Online Learning. Marketing Intelligence \& Planning 24(2), 148-157 (2006)

Gallivan, M.: Organizational Adoption and Assimilation of Complex Technological Innovations: Development and Application of a New Framework. The DATA BASE for Advances in Information Systems 32(3), 51-85 (2001)

Hamilton, P.M.: Implementing Local Pay: Rhetorically Analyzing Irritation. Personnel Review 27(6), 433-447 (1998)

Hamilton, P.M.: Attaining Agreement: A Rhetorical Analysis of an NHS Negotiation. International Journal of Public Sector Management 13(3), 285-300 (2000)

Hamilton, P.M.: The 'Vital Connection': A Rhetoric on Equality. Personnel Review 32(6), 694-710 (2003)

Hartley, S., Shepperd, S., Bosanquet, N.: Information Flows in the New Primary Care Organizations: Rhetoric Versus Reality. The Journal of Clinical Governance 10(3), 113 119 (2002)

Hughes, M.: NHS Managers as Rhetoricians. Sociology of Health and Illness (18), 291-314 (1996)

Kautz, K.: Information Technology Transfer and Implementation: The Introduction of an Electronic Mail System in a Public Sector Organization. In: Kautz, K., Pries-Heje, J. (eds.) Diffusion and Adoption of Information Technology, pp. 83-95. Chapman \& Hall, London (1996)

Kautz, K., Henriksen, H.Z., Breer-Mortensen, T., Poulson, H.H.: IT Diffusion Research: An Interim Balance. In: Baskerville, R., Mathiassen, L., Pries-Heje, J., DeGross, J.I. (eds.) Business Agility and Information Technology Diffusion, pp. 11-34. Springer, Boston (2005)

Kvasny, L., Truex, D.P.: Information Technology and the Cultural Reproduction of Social Order: A Research Paradigm. In: Baskerville, R., Stage, J., DeGross, J.I. (eds.) Organizational and Social Perspectives on Information Technology, pp. 277-294. Kluwer Academic Publishers, New York (2000)

Lamb, R., Kling, R.: Reconceptualizing Users as Social Actors in Information Systems Research. MIS Quarterly 22(2), 197-235 (2003)

McMaster, T., Wastell, D.: Diffusion - or Delusion? Challenging an IS Tradition. Information Technology \& People 18(4), 383-404 (2005)

Mingers, J.: Re-establishing the Real: Critical Realism and Information Systems. In: Mingers, J., Willcocks, L. (eds.) Social Theory and Philosophy for Information Systems, pp. 372406. John Wiley \& Sons, New York (2004)

Moon, M.: The Evolution of E-Government Among Municipalities: Rhetoric or Reality? Public Administration Review 62(4), 424-433 (2002) 
Moore, G.C., Benbasat, I.: Development of an Instrument to Measure the Perceptions of Adopting an Information Technology Innovation. Information Systems Research 2(3), 192-222 (1991)

Mueller, F., Sillince, J., Harvey, C., Howorth, C.: Discourse, Rhetorical Strategies and Arguments: Conversations in an NHS Hospital Board. Organizational Studies 25(1), 7593

Mustonen-Ollila, E., Lyytinen, K.: Why Organizations Adopt Information System Process Innovations: A Longitudinal Study using Diffusion of Innovation Theory. Information Systems Journal 13(3), 275-297 (2003)

Mutch, A.: Communities of Practice and Habitus: A Critique. Organization Studies 24(3), 383 401 (2003)

Myers, M.D.: Hermeneutics in Information Systems Research. In: Mingers, J., Willcocks, L. (eds.) Social Theory and Philosophy for Information Systems, pp. 103-128. John Wiley, Chichester (1994)

Myers, M.D.: Interpretive Research in Information Systems. In: Mingers, J., Stowell, F. (eds.) Information Systems: An Emerging Discipline?, pp. 239-266. McGraw-Hill, New York (1997)

NAO. The National Programme for IT in the NHS, Session 2005/2006, National Audit Office (2006)

Olmsted, W.: Rhetoric: An Historical Introduction. Blackwell Publishing, Oxford (2006)

Orlikowski, W.J., Baroudi, J.J.: The Information Systems Professional: Myth or Reality? Office, Technology, and People 4(1), 13-30 (1989)

Papazafeiropoulou, A.: A Framework for the Investigation of the Institutional Layer of IT Diffusion. Using Stakeholder Theory to Analyze Electronic Commerce Diffusion. In: Damsgaard, J., Henriksen, H.Z. (eds.) Networked Information Technologies: Diffusion and Adoption, pp. 167-179. Kluwer Academic Publishers, Norwell (2004)

Robertson, M., Swan, J., Newell, S.: Interorganisational Networks and the Diffusion Process: The Case of Networks not Working. In: Kautz, K., Pries-Heje, J. (eds.) The Adoption and Diffusion of Information Technology, pp. 147-159. Chapman \& Hall, London (1996)

Rogers, E.M.: Diffusion of Innovations, 3rd edn. The Free Press, New York (1983)

Rogers, E.M.: Diffusion of Innovations, 4th edn. The Free Press, New York (1995)

Rogers, E.M.: Diffusions of Innovations, 5th edn. The Free Press, New York (2003)

Sillince, J.A.A.: Resources and Organizational Identities: The Role of Rhetoric in the Creation of Competitive Advantage. Management Communication Quarterly (20), 186-211

Thompson, J.B.: Critical Hermeneutics: A Study in the Thought of Paul Ricoeur and Jurgen Habermas. Cambridge University Press, Cambridge (1981)

Timmons, S.A.: Failed Panopticon: Surveillance of Nursing Practice Via New Technology. New Technology, Work and Employment (18), 143-153 (2003)

Van de Ven, A.H., Schomaker, M.S.: The Rhetoric of Evidence-Based Medicine. Health Care Management Review 27(3), 88-90 (2002)

Vega, A., Chiasson, M., Brown, D.: Extending the Research Agenda on Diffusion of Innovations: The Role of Public Programs in the Diffusion of E-Business Innovations. In: McMaster, T., Wastell, D., Ferneley, E., DeGross, J.I. (eds.) Organizational Dynamics of Technology-Based Innovation: Diversifying the Research Agenda, pp. 379-392. Springer, Boston (2007)

Wainwright, D.W., Waring, T.S.: The Application and Adaptation of a Diffusion of Innovation Framework for Information Systems Research in NHS General Medical Practice. Journal of Information Technology 22(1), 44-58 (2007) 
Watson, T.J.: Rhetoric, Discourse and Argument in Organizational Sense Making: A Reflective Tale. Organizational Studies 16(5), 805-821 (1995)

Zaltman, G., Duncan, R., Holbeck, J.: Innovations and Organizations. Wiley \& Sons, New York (1973)

\section{About the Authors}

Imran Khan is currently a doctoral candidate and graduate teaching assistant at the University of Salford. His research interests center on large-scale, collaborative information systems development, organizational discourse, and rhetoric. He can be reached by e-mail at i.m.khan@pgt.salford.ac.uk.

Elaine Ferneley is a professor of Information Systems at the University of Salford. She can be reached at e.ferneley@salford.ac.uk. 